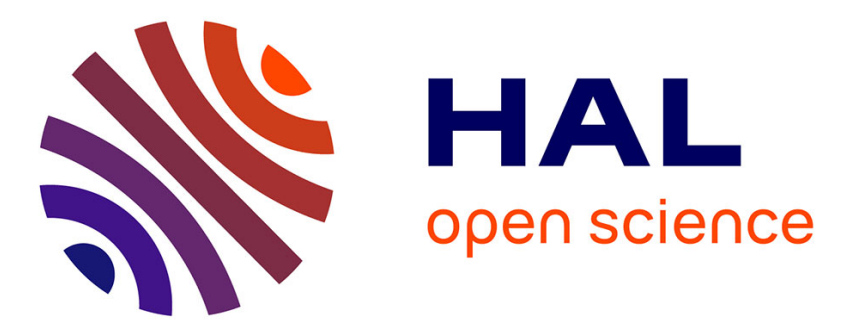

\title{
Inscribing Individuals into a Formalized System: The "Labour" Performed by Affective Spaces
}

\author{
Alexandra Toll, Melissa Mazmanian
}

\section{To cite this version:}

Alexandra Toll, Melissa Mazmanian. Inscribing Individuals into a Formalized System: The "Labour" Performed by Affective Spaces. Working Conference on Information Systems and Organizations (ISO), Dec 2016, Dublin, Ireland. pp.108-124, 10.1007/978-3-319-49733-4_7 . hal-01619190

\author{
HAL Id: hal-01619190 \\ https://hal.inria.fr/hal-01619190
}

Submitted on 19 Oct 2017

HAL is a multi-disciplinary open access archive for the deposit and dissemination of scientific research documents, whether they are published or not. The documents may come from teaching and research institutions in France or abroad, or from public or private research centers.
L'archive ouverte pluridisciplinaire HAL, est destinée au dépôt et à la diffusion de documents scientifiques de niveau recherche, publiés ou non, émanant des établissements d'enseignement et de recherche français ou étrangers, des laboratoires publics ou privés. 


\title{
Inscribing Individuals into a Formalized System:
}

\section{The “Labour” Performed by Affective Spaces}

\author{
Alexandra Toll ${ }^{1}$ and Melissa Mazmanian ${ }^{2}$ \\ ${ }^{1}$ Paul Merage School of Business, UC Irvine, Irvine, USA \\ alex.tolleuci.edu \\ ${ }^{2}$ School of Information and Computer Sciences, UC Irvine, Irvine, USA \\ m.mazmanian@uci.edu
}

\begin{abstract}
A substantial amount of ongoing work in organizations can be characterized as processes of formalization in which unique circumstances are rendered legible to organizational frameworks and inscribed into institutionalized ways of knowing and doing. Embedded in these processes is the need to manage, distance, and condition the affective and physical experience of the players involved. Using twelve months of ethnographic data gathered in the Family Law unit of the courts in a large county of California, we explore how formalization happens. We find that a dynamic combination of actants (technologies of formalization) engender affective spaces that serve as passage points in the process of formalization. These affective spaces condition the bodies and emotions of customers in a manner that generally mitigates unstable intensity and renders the customer ready to focus on the "facts" of the case. We suggest that by attending to the multiple actants in an environment we are able to interrogate both the origin and effects of "affect" as well as better understand how key passage points work in the service of formalization processes. In so doing we expand the conversation about the challenges of public service delivery and put forth the beginning of a theory of how affective spaces serve organizational and institutional goals.
\end{abstract}

Keywords: ethnography $\cdot$ practice $\cdot$ sociomateriality $\cdot$ affect $\cdot$ formalization $\cdot$ process $\cdot$ inscription.

\section{Introduction}

Processes of formalization occur in numerous organizational and public contexts. Despite longstanding attention to the design and outcomes of formalization in organizations literature, little is known about the enacted and situated process through which formalization is made to happen on an ongoing basis. Beyond the creation of roles, rules, and procedures, maintaining relatively stable formalized processes requires ongoing and effortful attention to the translation and inscription of its inputs. Formalization ${ }^{1}$ creates distance between an account and its inscribed form; it serves as a point of transition from a complex state to a streamlined mold. Embedded in this process is the work involved in managing, distancing, and conditioning the emotional and physical experience of the players involved. Thus, this research asks how formalized systems are made to happen in ongoing organizational practice.

The courts provide a rich context in which to study the ways in which formalized processes are enacted and re-enacted in everyday work. In Family Law, court employees and litigants interact in periods of complex

${ }^{1}$ Formalization, as defined in Dictionary.com, involves "giv[ing] a definite form or shape [in order] to state or restate in symbolic form". 
family crises - divorce proceedings, child custody arrangements, and domestic violence disputes. ${ }^{2}$ Moving such activities towards resolution requires that a complex and messy personal issue be rendered into a form legible to the courts and amenable to formalization. Thus, it is an ideal environment to examine the multiple social, spatial, and material ways in which the individual experience is modified, tamed, and brought into line with codified organizational practices of translation and inscription in a particularly charged environment. In so doing we shed light on the layers of affective, emotional, and physiological experience that condition and are conditioned by dynamics of formalization.

Through data gathered from a twelve-month ethnographic project in the Family Law unit of the courts in a large county of California, we highlight the ways in which the spaces of service encounters engender a particularly potent affective environment that conditions the process of formalization. We propose that such affective spaces form key passage points through a process of rendering messy inputs amenable to formalization. Further, the technologies of formalization employed during these passage points condition the bodies and emotions of customers ${ }^{3}$ in a manner that generally mitigates unstable intensity, easing a process of formalization and rendering a negatively charged environment into a seeming rationalized and controllable space.

\section{Literature}

Formalization processes have been a topic of considerable inquiry in organizations literature and play a central role in Weber's conceptualization of the bureaucratic organizational form. Formalization involves "the extent of written rules, procedures, and instructions" for the accomplishment of work tasks [1, 2]. Existing literature on formalization highlights its importance to the effectiveness of organizational work, ensuring role and task clarity [1], enabling coordination [2,3], and providing a "common language" through the codification of tacit knowledge [4]. Given the positive outcomes related to effective formalization systems, current work has begun to postulate about how to design enabling formalization systems for employee fulfillment and organizational performance and flexibility under complex and uncertain conditions [1], [5]. In examining the precursors and the effects of formalization systems, however, current scholarship has tended to overlook the ongoing, enacted and situated processes of rendering formalization systems viable once they are put in place in organizations.

As Vlaar et al. highlight, formalization is more than just an output (i.e. rules, procedures, contracts), but also "the process of codifying and enforcing outputs and behaviors" [6] (p. 439), [7]. A substantial amount of work in organizations can be characterized as ongoing processes of formalization achieved under unique circumstances involving inputs from external actors. In such cases, unique accounts of individuals are rendered legible to organizational frameworks and inscribed into stable, institutionalized formal procedures. The critical tasks of translating and inscribing individual accounts into a formalized system require ongoing work from organizational employees to manage, distance, and condition the emotional and physical experience of the actors so as to facilitate the process of formalization. However, scholars acknowledge that such behavioural aspects of formalization have been mostly overlooked $[8,9]$.

While Weber's [10] conception of the bureaucratic form highlights "formalistic impersonality" as a critical attribute that serves to eliminate or mitigate irrationality, emotionality, and friction [11], the role of affect in processes of formalization remains undertheorized [8]. A growing literature on emotional labour, "the silent work of evoking and suppressing feeling" [12] (p. 7), provides a starting point for this exploration, highlighting the invisible labour required of employees to provide "good service". In this research, however, we emphasize the affective elements of this process rather than focusing on the emotional labour required of

2 The majority of Family Law cases are self-represented. Under such circumstances, the need to create effective formalization processes becomes all the more pronounced, as parties lack familiarity and preparation with court proceedings. This creates challenges for all aspects of the formalization process.

3 "Customer" is an emic term used by administrative employees of the courts for all people they serve and interact with - litigants, family members, etc. 
organizational employees in order to account for the spatial and material elements that comprise the spaces in which this process is performed.

In so doing we build on the affective turn of the last few decades in the humanities and social sciences. Such scholars have taken the focus in the study of affect away from the realm of the cognitive and subjective to consider the realm of bodily capacities. Clough conceptualizes affect as "bodily capacities to affect and be affected", and suggests that such a conceptualization allows affect to be considered "in relation to the technologies that are allowing us both to 'see' affect and to produce affective bodily capacities" [13] (p. 2). This perspective opens the door for more holistic and comprehensive accounts of "affective labour" that go beyond the experience of one actor - traditionally the employee - in a complex system of labour. A focus on affect allows us to look beyond the "world of interiority of the human subject" [14] (p. 12) in order to focus on the ways in which the affective environment is designed, managed, and rendered productive.

Space is not a mere container for interpersonal exchanges; affective labour is conducted in active spaces. Reckwitz suggests that attention to the interplay between affect, artifacts, and spaces can be achieved through the study of practices enacted in "affective spaces", bringing attention to the idea that "affects are often directed at artefacts and objects and are structured by the spaces these artefacts and objects form" [15] (p 254). Affective labour, therefore, involves the enrolment of the layout of a space, the physical artifacts within it, the social norms that colour and shape assumptions, and the highly charged psychological and physiological bodies who interact in an affective space.

In this paper we interrogate how people, objects, and elements of physical space come together in two key affective spaces of the Family Courts. We employ an actor-network theoretical (ANT) perspective [16, 17] in order to give equal consideration to the human and material actors, or actants, involved in this process. We find that ANT terminology provides a lens and a language with which to explore formalization as comprised of processes of translation, "the mechanism by which the social and the natural worlds progressively take form" [16] (p. 19) and inscription, "the result of translating one's interest into the material form" [18] (p. 143), [19]. We suggest that formalization is made up of points of transition, obligatory passage points that serve to move actors "smoothly between different specificities and their materialities" [20] (p 205). Such passage points make court employees critical to the network and enable them to enrol customers and technologies of formalization to enact, legitimize, and stabilize the formalization process in support of organizational goals [16], [21].

We argue that by taking this perspective we are able to shed light on how the emotionally laden process of translating and inscribing personal family issues (e.g. divorce, domestic violence, child custody arrangements, etc.) into a formalized system works in practice. After reviewing our methods, we describe spaces that serve as key passage points in the formalizing process (i.e. the Self Help corridor and Clerks' office). We then present a suite of technologies of formalization such as physical layout, dress, information systems, and office supplies, and discuss how each works to prepare individuals and shepherd them through the practice of inscription. Finally, we examine how the threat of breakdown (or unwanted explosion of emotion) infuses ongoing practices and pervades the environment of each space. We conclude with a discussion of the role of passage points in maintaining and enabling formalized processes.

\section{Data and Methods}

This project is part of an ongoing ethnographic study in which we are investigating the work practices of the court in light of a new content management system's implementation. Thus far, we have collected twelve months of data from various departments within the Family Law unit of the court. Data include field notes from over 100 hours of observations, interviews with 50 court employees, and observations during various executive and operational meetings. In this paper we use a subset of these data to examine the practices and interactions that occurred within the Self Help and Clerks' offices. Specifically, the first author's observations of the Self Help office and the Clerks' office conducted during court visits ranging four to eight hours in length once or twice a week over approximately 70 hours were used. These observations were recorded in journals and then transcribed into copious field notes describing the layout of the spaces and interactions between employees and customers. In the course of observations, the first author engaged in numerous conversations with court employees. Such informal interviews were also recorded in daily field notes and 
transcribed as comprehensively as possible immediately after each visit. The first author took the stance of interested observer, combining at a distance observation and note taking with brief questions to court employees during breaks and transition times. The researcher dressed much like the court employees and was relatively unobtrusive. We have no reason to believe that she was obvious to customers of the court and she did not interact directly with this population.

Data were analysed using an inductive approach to theory building, reviewing field notes, transcripts, codes, and themes. In the course of this analysis, the assumptions and key concepts of actor-network theory resonated with us in two key ways: ANT provided a flat ontology with which to give equal consideration to people, objects, and spaces and provided a rich language with which to describe these actants and theoretical frames such as "translation", "inscription", and "passage points" that provided theoretical inroads towards making sense of these data.

Using a grounded theory approach $[22,23]$ we first noticed the importance of the Self Help and Clerks' offices in getting people "through" the system and making progress on resolving whatever issue brought them into court. Thus, we first coded these data with an eye towards the individual experience of moving through the process of resolving an issue. In theorizing how the individual was affected by the material, physical, and social environment of these particular spaces we then conducted a second round of theoretical coding examining how bodies, objects, and elements of the physical space played into this process. These insights helped us see the Self Help and Clerks' offices as affective spaces that acted as key passage points through a highly codified bureaucratic system. Throughout the process of coding, the first author wrote theoretical memos that were shared and debated between authors.

\section{Findings}

The Self Help and Clerks' offices are tasked with dealing with difficult situations and getting to moments of temporary resolution, whether it be the next step in case processing or managing an emotional outburst. These steps delineate and propel movement through a process of transforming complex situations into inputs amenable to the existing formalized system. These offices provide multiple forms of "passage": legal transition from no file to an official case file; physical movement of information from the outside to the inside of the court's offices; symbolic movement from a private matter to public matter and from problem to resolution. They provide a passage from the uniquely personal and emotional experiences of customers into streamlined and rationalized legal accounts of a case. In order to gain traction on how these passages happen, we examine the spaces in which these transitions take place. After providing an empirical description of two key passage points, we examine how organizational and institutional goals are accomplished in these affective spaces through various technologies of formalization.

\subsection{Empirical Description of Passage Points}

Self Help. The Self Help office is located on the first floor of the court building. The line outside of Self Help often extends along the perimeter of the first floor, making its way around the boxed hallway that surrounds an open staircase at the centre of the room. Customers queue up in the lobby of the court before entering the Self Help corridor (which sits outside the main Self Help office). Bright, fluorescent light permeates the hallway into the Self Help corridor.

At any point in time, the line for Self Help services usually has ten to fifty customers. On average, customers wait between twenty minutes to an hour before they make it to the threshold of the Self Help corridor. There are no chairs in the first floor hallway, but a wide ledge surrounds the centre staircase and customers who are waiting for help or filling out paperwork sit on it. Customers waiting to gain entry into the Self Help corridor must stand in order to secure their spot in the line.

Only a handful of customers are allowed to enter the corridor that precedes the service windows. Once a customer makes it inside the corridor, they are able to see the service windows. Upon reaching the entryway, customers typically wait an additional ten to twenty minutes to be called to a window. 
Four service windows help customers. A clear sheet of plastic separates the employee from the customer at each window. A slate at the bottom of the plastic sheet is intended to allow customers and employees to move paper from one side to the other. A circular opening strategically placed at the centre of the plastic sheet is meant to allow conversation between customer and employee. The four windows are partially enclosed, and employees and customers can hear each other's conversations. The windows are housed in a tight rectangular office space. There is just enough room for the employees' workstations that accommodate their office supplies and computers, where they log customer tickets in an online tracking system or use the case management system to look up case information.

The workstations set up at the first three windows are standing stations. Employees either stand or sit at tall bar stools as they help customers. The fourth window is for disabled patrons, so the employee is seated behind the desk in a regular chair. The design is intended to mimic the height at which customers will be standing or sitting when they come to the windows and to allow customers and employees to engage at eye level. Two printers are placed between workstations. At the far end of the windows, a door leads to the Sheriff's break room.

The space in the corridor is cramped and people are constantly moving in and out. Only the customer requesting help may approach the window. The constant flow of people, the bright lighting, the hum of conversations between employees and customers, and the constant buzz of printers creates a loud environment.

After obtaining information at a service window, customers are asked to complete necessary paperwork and return for a document review consultation. Many customers complete their paperwork inside the court building and return for document review on the same day. Customers who request document review wait in the first floor lobby of the court building (the same area where the line for help at the windows is formed) and are called into the main office by one of the paralegals.

A large room next to the Self Help windows houses employee cubicles where paralegals provide document review consultations. A large centre table provides a makeshift consultation area. Often document review takes place at the centre table, and paralegals go back and forth to their desks to look up information on their computer. Self Help employees typically end customer interactions by directing them to the seventh floor where the Clerks' office is located and handing them a yellow post-it note with the office's location in order to file the paperwork that has just been completed.

Clerks' Office. The Clerks' office houses public filing windows where customers submit paperwork and obtain appointments for court hearings. The line to enter the Clerks' office windows extends into the hallway and wait time ranges from ten minutes to an hour. There is a check-in window on the right hand side of the room and eight filing windows line the left side.

The check-in window is enclosed with clear plastic like a fish bowl. Once customers check in to the Clerks' office, they obtain a number that will be used to call them when a clerk is ready to process their request. A waiting area is located across from the filing windows. Guests may accompany customers to the waiting area but cannot approach the windows. Once inside the waiting area, customers typically wait an additional ten minutes to an hour and a half to be called.

Waiting customers face the filing windows like an audience at a theatre; chairs are set up in four rows of twelve seats each. The seating area is dimly lit; occasionally customers bring their own books or magazines to squint over and pass the time. Often people are playing with their smart phones. A sign at the entrance asks people to silence their phones while in the office. The room is relatively quiet, although it can get loud depending on the time of day and the number of people who are waiting; a few people nod off as they wait for their turn. To the far right of the filing windows is a separate area that houses kiosks for electronic file review. Customers sit at computer workstations where they can review information from their case file.

The filing windows are set up in a similar fashion to the Self Help windows, but the space is larger and customers have more privacy when addressing the filing clerk. Since there is more room between each window, it is hard to hear other conversations, but not impossible. Each window has a pane of clear plastic in front of it that separates the employee from the customer with slots that allow employees and customers to hear one another and to pass information from one side to the other. An opaque sliding partition allows employees to close off their space from customers' view. Clerks may ask customers to take a seat while they 
process their request and then proceed to close the sliding partition until they are ready to call the customer back to complete the service transaction.

The main office space for case processing is located behind the filing windows. Cubicles line the back side of the room and employees who are not interacting with customers sit at their cubicles and process paperwork into the case management system. The office space is lined with shelves that contain paperwork yet to be processed as well as forms that must be sent to Records for digital scanning. The constant buzz of printers and continual stamping of paperwork is difficult to ignore.

\subsection{Technologies of Formalization}

By framing the Self Help and Clerk's offices as affective spaces that serve as passage points we are able to gain traction on how the practices of translation and inscription into legible court case files is performed and how these practices serve to animate the system of formalization in the courts. These technology-mediated work practices involve the coming together of physical spaces and workplace norms in service of organizational and institutional goals. We refer to this dynamic combination of actants as technologies of formalization, as they serve to engender affective spaces and to manage an inherently unstable environment. Examples of technologies of formalization include space (the physical and sensory space in which these interactions take place), style (as evinced by material elements such as dress as well as communication practices and organizational norms), and objects (the artifacts that participate in the service transaction). Next, we explore the ways in which these various technologies constitute and serve the ongoing processes of formalization. We highlight how they serve, occasionally undermine, and render possible the processes of translation and inscription that underlie formalization.

Space. We find that the physical and sensory spaces in which customers obtain help and file their paperwork configure the body in specific ways. Customers wait in line for lengthy periods without chairs or entertainment to minimize or distract from their bodily discomfort. The lighting is either too bright or too dim. Noise abounds. Customers are expected to endure this embodied experience without complaint and, in so doing, we assert they become physically disciplined into an emotional and physical state that eases the process of inscribing their experiences into the formalized system.

In addition to the physical/sensory spaces of waiting, the material experience of interacting with a court employee serves to manipulate the customer in ways that enable formalization. The plastic panes and partitions that enclose the windows serve to create distance between employees and customers by forcing bodies to strain and bend in order to effectively communicate. Partitions both stifle and carry sound and hinder visibility. Court employees are aware that interactions with customers are strained based on the embodied difficulties. During a tour of the Self Help office, David ${ }^{4}$ the supervisor, acknowledged the limitations of the space.

Whoever designed these offices didn't know what they were doing. See the partitions? Sure, they are there to protect the employees but they make it hard to hear. The room gets so loud. And the fact that they are partial makes it so that the conversations blur together. I am one of the loudest employees in the unit, and when I am helping someone, it is hard for the others to hear. And, look at the openings for the customers to talk to the employees. They are too high for most of our customers. So they end up bending over and using the slots for paper to communicate. They press their ears against the plastic in order to hear better. And the space is so cramped.

A close examination of these spaces reveals that the embodied experience they engender mirrors the nature of the tasks performed within them. The formalization process requires an active effort to delineate the boundary between private crisis and public record. Court employees are expected to translate customers' stories and mold the narrative of the case into "rational facts" that are intelligible to the case file template. Similarly, the physical spaces of service interactions create barriers that separate customers from court employees, break up their experience into different lines and rooms, and generate bodily discomfort that forces customers to contort and to mould themselves for the encounter. We argue that the affective and embodied experience of becoming ready to fill out and submit the necessary forms matters. This experience

\footnotetext{
${ }^{4}$ Pseudonyms were used in place of the names of court employees in order to preserve anonymity.
} 
serves to prime the customer to accept a modularized and condensed version of a highly personal and often emotional narrative. The uncomfortable and overloaded body is a body prepared to give binary answers to difficult questions and strip details from a story that are not necessary to the formalized system.

Style. In addition to spatiality, a focus on affective spaces draws attention to the socio normative environment where interactions take place. The style, demeanour, and approach of court employees are critical to creating a passage point from private to public. Court employees dress in professional attire, a stark contrast to the casual garb of customers. The employees' speech and demeanour also highlight their institutional knowledge - in contrast to the lack of knowledge carried by the many self-represented litigants in Family Court who are interacting with the courts for the first time. The customers' transition into an institutional realm is punctuated by these forms of disparity that bring into relief the customers' need to find guidance in these passage points.

Further, the assumed formality in the speech and dress of the employees creates a barrier between them and those they are serving. This barrier legitimates a particular form of interaction - kind, but businesslike. The employees' otherness can serve to jolt a customer out of the emotionally laden complexity of a situation and narrow in on the need to know the facts. When discussing his approach to engaging customers at the Self Help window, David highlights the importance of narrowing in on the facts with pointed questions. "After greeting them", David notes, "I immediately ask for their zip code and turn to my screen to type it in. I need the zip code anyway for my stats and this forces them to snap into the moment and to focus on giving me the information that I need in order to help them".

By asking a simple question David creates a neutral starting point with which to engage customers and move them through this key passage point. Like David, Sam, a lead clerk at the Clerks' office, engages customers in a friendly manner but opens with a question that highlights her position in the exchange as the professional who needs information in order to lend her expertise to the situation:

I am always friendly and professional with the customers. But I get a feel for what they are trying to share with me. Are they giving me information that I need? If they are venting, I feel for them, but I have to focus the conversation. I'll politely stop them and tell them that I need to focus on processing their paperwork in order to get it right. Sometimes, I'll tell them to take a seat while I process their paperwork and that I will call them back to the window when I am done. I then turn to my computer and start typing or searching the system. If it is loud or if they keep approaching me to talk, I politely close the window so that I can focus on what I am doing. When I call them back, I explain everything I've done in detail and what they have to do next.

Sam's ability to distance herself from the potentially emotionally charged nature of the exchange serves multiple functions. Her continual work to bring the focus of the interaction back to its practical and "productive" elements (e.g. case filing, calendaring of hearings, etc.), while remaining professional and courteous serves to both guide and control the customer. Sam's formal dress, polite demeanour and professional persona work in strange alignment with the embodied experience of waiting prior to reaching her. Sam guides the storytelling while implicitly managing the possibility for emotional spillover by the customer. This process is made easier because the customer has been rendered ready through the waiting process.

While not every customer will respond to the affective environment in the same manner, we witnessed the effects of these affective spaces on drawn faces, docile bodies, and a willingness to answer questions about complex scenarios with short and truncated responses. Thus, we argue that the sensory, physical, and socio normative aspects of these affective spaces work together to guide the customer forward in the processes of translation and inscription that constitute formalization.

Objects. In addition to managing the affective spaces in which service takes place, a variety of tools and objects perform the work of inscribing case files throughout the service encounter. These tools include the computers and embedded case management system in which records are ultimately codified, the paper forms in which information is captured and streamlined, and the office supplies that are used to direct, highlight, erase, and organize customer information into the form that is required for processing.

David, for example, literally wears his tools around his waist. An actual belt contains a stapler and staple remover, highlighters, ballpoint pens, whiteout pens, and post-it notes. The office supplies in his tool belt serve to manage the interaction and direct the flow of information through the passage point. Similarly, the following encounter between Sylvia, a paralegal in the Self Help office, and Mary, a customer involved in a document review consultation, exemplifies the use of office supplies to direct attention to and guide the process of translation and inscription. 


$\begin{array}{ll}\text { Sylvia: } & \text { Hi, can I take a look at your packet? } \\ \text { Mary: } & \text { Yes, here it is. I wasn't sure how to fill out some of the sections... } \\ \text { Sylvia: } & \text { OK, let me take a look. } \\ \text { Sylvia: } & \text { Are you requesting spousal support? } \\ \text { Mary: } & \text { I just want money for my kids. I don't need anything else from him but to be responsible... }\end{array}$

As she is talking, Sylvia takes another pen from the bin at the centre of the table and hands it to Mary. Mary grabs it and looks at the paper. She stops talking in order to review the portion of the form that Sylvia is pointing out. Once Mary pauses, Sylvia asks her another question.
Sylvia: $\quad$ Do you want to be able to seek spousal support at a later time?
Mary: I don't know. What should I do?
Sylvia: I can't give you legal advice. You need to fill out this section if you want to be able to seek spousal support at some point or fill out this other box if you do not.

Sylvia points to the two check boxes. She has highlighted this section to make it easy for Mary to see. Mary reads the two prompts next to the check boxes and hesitantly marks the box requesting spousal support. Sylvia takes the paper again and continues reviewing Mary's entries.

In this exchange, Sylvia strives to complete the document review session, attend to Mary's questions while eliciting information required to complete the form, and guide Mary in completing the form accurately without giving her legal advice. ${ }^{5}$ Familiar office tools enable Sylvia to guide Mary through document review and focus on the information required by the system. By simply highlighting the section of the form that requires attention, Sylvia's actions lead Mary to suspend her emotional response to her husband's act of abandonment and to simplify the decision to the selection of a check box.

In some cases, however, tools undermine the practices of codification and inscription necessary for the formalization process. The electronic case management system, for example, contains a record of every interaction between the customer and the legal system so as to facilitate case processing within the court. However, a computer screen that displays all case records, when visible by the customer, threatens to expose the complex links between multiple elements and, in so doing, complicate the practice of inscription (in which information needs to be presented as linear and distinct). As Sylvia describes:

The main reason that I use the centre table for consultations is that I don't want customers looking over my shoulder at the computer screen. If they are here for document review, I want us to focus on the document that they are getting ready to submit. If we sit at my desk and they look at their case online, they start asking questions about other documents and the status of the case and the consultation gets out of control. This way, every time we need to consult something in the system, I have to stop and walk over to my desk. It forces them to think through what they want to ask and what they tell me about their case.

Table 1 summarizes the various technologies of formalization, highlighting their functions and various roles they play in the process. They inform, constitute, and shape the process of formalization by enabling practices that limit, control, and bottle the potential intensity of the emotional exchange. As such we find these key passage points serve as affective spaces that anesthetize potentially negatively charged environments into seemingly regularized and controlled environments oriented around the practical elements of case processing.

Table 1. Technologies of Formalization

Technologies of FormalizationExamples
Role (inform, constitute, and shape the process of formalization)

Materialize and constitute the formalization process through modularization and delineation Draw attention to the physical and material through bodily discomfort

\begin{tabular}{lll}
\hline Space & $\begin{array}{l}\text { Physical layout (rooms, service windows, } \\
\text { consultation table, etc.) }\end{array}$ & $\begin{array}{l}\text { Materialize and constitute the formalization } \\
\text { process through modularization and delineation }\end{array}$ \\
Lines & $\begin{array}{l}\text { Draw attention to the physical and material } \\
\text { through bodily discomfort }\end{array}$ \\
Plastic partitions & \\
Sensory elements (lighting, noise, etc.) & \\
\hline
\end{tabular}

\footnotetext{
${ }^{5}$ Court employees must limit their interactions to the provision of legal information. Providing legal advice without being the attorney of record on a case is punishable with a fine. Family Law Facilitator Act, Family Code Sections 10000-10015.
} 


\begin{tabular}{|c|c|c|}
\hline Style & $\begin{array}{l}\text { Dress } \\
\text { Communication practices } \\
\text { Organizational norms }\end{array}$ & $\begin{array}{l}\text { By rendering something formal right away, } \\
\text { create a barrier or distance from the emotional }\end{array}$ \\
\hline Objects & $\begin{array}{l}\text { Computer screen } \\
\text { Case management system } \\
\text { Case forms } \\
\text { Office supplies (highlighter, whiteout pen, } \\
\text { stapler, filing stamp, etc.) }\end{array}$ & $\begin{array}{l}\text { Focus attention on the practical elements of the } \\
\text { case } \\
\text { Help to streamline and simplify the complex } \\
\text { narrative of a case }\end{array}$ \\
\hline
\end{tabular}

\section{3}

\section{Preparing for Breakdowns}

Various forms of breakdown threaten the environment and stability of these affective spaces, thereby compromising their viability as anesthetizing and effective passage points. Breakdowns can occur at various levels of the organizational chain; examples include communication and material failures during the service encounter (e.g. emotional outbursts, lost or missing paperwork, etc.) and organizational process changes or disruptions (e.g. the implementation of new technological systems, backlogs, etc.). Next, we examine examples of breakdowns and the ongoing efforts involved in anticipation and reaction.

Communication failures. A customer who arrives at the courtroom in an angry and anxious state may find him or herself increasingly frustrated about the wait as he/she makes their way through a line. Such an accumulation of anger, anxiety, and frustration may not always dissipate over the course of accommodating the body to the embodied experience of waiting and travelling through lines and inuring the senses to this particular environment. In fact, such an environment might foment an angry outburst when a customer is confronted with an upsetting fact or confusing instruction. In these moments, court employees are confronted with an unruly situation. David, the Self Help supervisor, explains the ways in which he and his staff respond to emotional outbursts at the service window.

When someone comes in here and starts yelling and making a scene, we do the best we can to calm them down, help them, and get them going. Then, it is all hands on deck. We all go to the other side of the windows with clipboards and pens in hand. We try to serve the customers who were in the office at the time of the outburst quickly and get them going. We smile and get them help quickly. We wait to bring other people in. We clear the air. We need to clear the air. We can't have these kinds of outbursts affecting the mood of the room. People come in here with problems and if the air is tense, they feel it and it affects them. It is all hands on deck and we clear the room as quickly as possible. Once we've cleared the room, we can go back to normal. We get behind the windows and then bring in a new batch. But, we've cleared the air and manage to get the negative energy out.

When negative emotions surface and disrupt the order that is negotiated by the formalization process, employees find ways to break the distance between themselves and customers and to increase the pace of service delivery. As David's approach suggests, technologies of formalization are temporarily set aside. Court employees remove themselves from the plastic enclosures that create a physical distance from customers; they move away from the computer screens that take their gaze away from customers; they increase smiles to break the demeanour of professional experts. New tools are enlisted to regain stability. In these cases, clipboards serve a special purpose. They call into being temporary surfaces that facilitate inscription while allowing employees to stand next to their customers. This enrolment of new tools and strategies suggests that employees actively foster the emergence of a new, if temporary, affective environment - one through which the "negative energy" is cleared out.

Process Changes and Disruptions. Breakdowns also occur within the organization. Changes in organizational process have a direct effect on the affective spaces of work. For example, the recent introduction of a new case management system caused a great deal of anxiety and frustration among employees. Managers launched an internal campaign to ease tension; their slogan was "Keep Calm and Odyssey On". Signs were posted throughout the building for customers to see and read, "Please be Patient Information Loading". In addition, during the first week of implementation, back office employees were asked to work the lines of waiting customers, carrying clipboards and checking on customers. Throughout 
this week, employees were asked/allowed to wear casual clothing. Tina, the manager of the Family Law Unit, explains that the reasons behind this procedural change were twofold:

During [system] go live, we had employees here wearing T-shirts and jeans. It was casual day every day. We knew they were hurting and we wanted them to be comfortable. We also wanted to let customers know that something was going on, that we were going through something; we were not at our best. So, we dressed casually. We were one of them [the customer] for the week. We were walking around and talking to them, calming them down and sharing in their frustration. It humanized us. They saw we were human; we were one of them, and we were trying our best.

Such change challenges the institutional authority and expert status of court employees. The same style and demeanour of court employees that once facilitated passage into a particular institutional sphere now create dissonance, as they lose status as a marker of expertise. In order to manage this tension between a formal, structured environment and a new, unstable, and evolving practice, managers actively dismantle technologies of formalization into more intimate and human elements. Such an approach to the crisis has the potential to create a different kind of bond between employees and customers, one that will engage both of them in a relationship of co-creation of the case through mutual questioning and learning.

Table 2 summarizes the forms of breakdown that emerged in our data collection. We witnessed a transformation of the sociomaterial and affective space that emerges in response to breakdown. However, there are costs involved in such a transformation. It involves fundamental changes to the practices, pacing, and embodied experience of work. Away from their computer and armed with only paper and clipboards, employees must find time to complete the work of creating and modifying electronic case files after a service encounter rather than alongside it. Furthermore, fostering a qualitatively different affective environment through more intimate customer encounters and a heightened awareness of negative emotions (in both customers and employees) involves new tactics and practices that may increase emotional strain. Understanding the preparations involved in dealing with the threat of breakdowns in key passage points highlights the ways in which technologies of formalization are effortful elements of a process that is generally experienced as, stable, effective, and normalized to those within it.

Table 2. Breakdowns

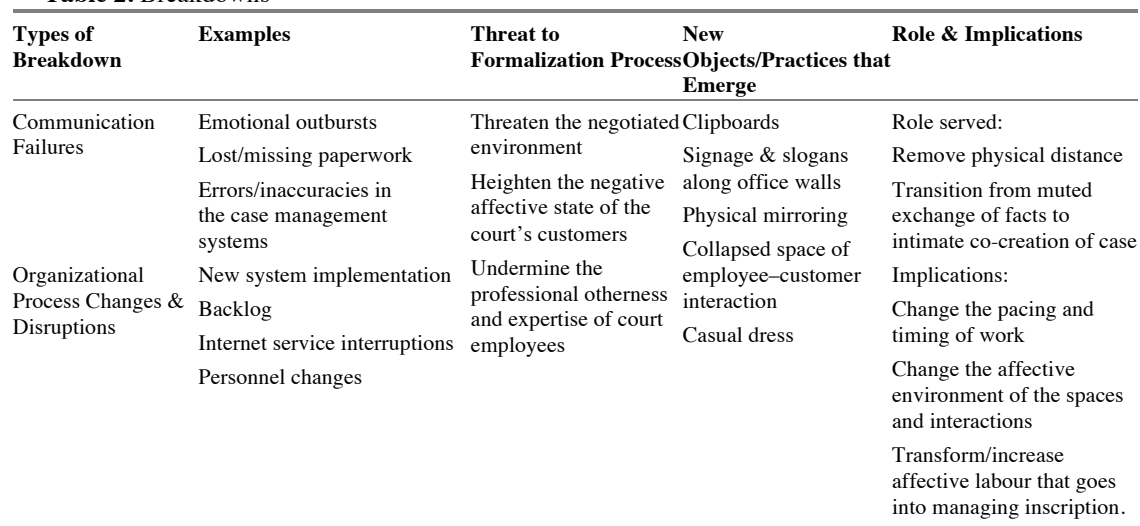




\section{Discussion}

In the courts, the Self Help and Clerks' offices provide points of transition from private family crisis to public record, from messy stories to formalized inputs. Our analysis provides a deeper understanding into how these messy and unstable practices of translation and inscription happen. The two key passage points involved in this process are critical to the successful enrolment of customers into the system. They embody the transition from discomfort to relief, mimicking the transition from problem to resolution that customers seek.

As Callon articulates, "the notion of translation emphasizes the continuity of displacements and transformations which occur in [a] story" [16] (p. 18). In this process, displacements occur along and within each passage; displacements of negative emotion and personal crisis into physical discomfort are followed by displacements of physical relief into an affective environment that renders the inscription of customer accounts into the system possible. Customers must wait in long lines, stand for extended periods, and endure affective discomfort before they make their way into these offices. Upon reaching their destination, they find moments of relief and attention to their needs. In these moments, translation and transformation into the formal system are possible with the active enrolment of technologies of formalization that displace individual interests into mutual accommodation in service of the formalization process. Technologies of formalization enable displacements of physical relief and emotional exhaustion into affective neutrality, enabling the process of translation and inscription into the legal system.

The passages that are afforded within these spaces may not be pleasant but they are productive in so far as they enable movement along the system [20]. Without bowing to questions of organizational design or human intentionality, we argue that the affective flows called into being through the various technologies of formalization in these key passage points serve organizational and institutional goals. In sum, these spaces condition the bodies and emotions of customers in a manner that generally mitigates unstable intensity and renders the customer ready to focus on the "facts" of the case, as delineated by the legal system.

This effect appears to be in line with theories of bureaucratic structure and its ability to elicit affective neutrality [10], [24]. However, the lens of affective spaces suggests that achieving an agentic engagement with an organization does not emerge in a vacuum. Rather, the anesthetizing quality of the bureaucratic interaction is a product of the affective spaces that bring into possibility certain processes of formalization. Such spaces serve to stabilize the formalization process in support of individual, organizational, and institutional goals. It is in the interest of individual customers to successfully translate and inscribe his/her unique situation into the formalized system in order to realize a desired goal (e.g. divorce, custody arrangement, restraining order, etc.). It is in the interest of the organization that the formalized system "works" such that influx of inputs are made codifiable and actionable and effective outcomes are achieved. And it is in the interest of the institution that legal service appears stable, consistent, and legitimate. Thus, we argue that affective spaces are a critical aspect of both specific formalizing practices and the maintenance of bureaucracies more generally.

On a different note, a move towards virtualizing service encounters through information systems poses new challenges. In establishing how affective flows in key spaces foster formalization processes, this work calls into question the assumption that customers would be better "served" by a virtual process that removes physical discomfort and interpersonal interaction when establishing cases in Family Law. Having outlined the importance of space, people, and materials in the enactment of effective inscription, the removal of these very elements requires a new way of thinking about how organizational and institutional goals may be achieved through new media and in the absence of spatial and affective management.

\section{Conclusion}

In this paper we examine the ways in which physical space, objects, and flows of affect serve the organizational and institutional goals of translation, inscription, and formalization. Making the personal public and legible to a formal institution is a precarious endeavour. We argue that translating volatile personal issues into an institutionalized system and moving a case and its parties to a legally recognized "resolution" is an ongoing and effortful accomplishment brought into being by numerous actants. By embracing how 
bodily experience and emotions are conditioned in this sociomaterial space, we are able to shed light on how this process of formalization is made to happen. In so doing, we look beyond human intentionality to explore the multidimensional forms of "labour" that go into taming the individual experience and act in service of organizational and institutional goals.

In sum, this paper proposes an ontological shift in understanding "affective labour" and the affective practice of translation, inscription, and formalization. We suggest that by attending to the multiple actants in an environment that, consciously or otherwise, produces and reproduces "effective" affective spaces, we are able to interrogate both the origin and effects of "affect" as well as better understand how key passage points work in the service of formalization processes. In so doing we expand the conversation about the challenges of public service delivery and put forth the beginning of a theory of how affective spaces serve organizational and institutional goals.

\section{References}

1. Adler, P.S., Borys, B.: Two Types of Bureaucracy: Enabling and Coercive. Administrative Science Quarterly. 61-89 (1996)

2. Battilana, J., Sengul, M., Pache, A.C., Model, J.: Harnessing Productive Tensions in Hybrid Organizations: The Case of Work Integration Social Enterprises. Academy of Management Journal. 58(6), 1658-1685 (2015)

3. Canales, R.: Weaving Straw into Gold: Managing Organizational Tensions between Standardization and Flexibility in Microfinance. Organization Science. 25(1), 1-28 (2014)

4. Grimaldi, R., Torrisi, S.: Codified-Tacit and General-Specific Knowledge in the Division of Labour Among Firms: A Study of the Software Industry. Research Policy. 30(9), 1425-1442 (2001)

5. Wouters, M., Wilderom, C.: Developing Performance-Measurement Systems as Enabling Formalization: A Longitudinal Field Study of a Logistics Department. Accounting, Organizations and Society. 33(4), 488-516 (2008)

6. Vlaar, P.W., Van Den Bosch, F.A., Volberda, H.W.: Towards a Dialectic Perspective on Formalization in Interorganizational Relationships: How Alliance Managers Capitalize on the Duality Inherent in Contracts, Rules and Procedures. Organization Studies. 28(4), 437-466 (2007)

7. Ouchi, W.G.: A Conceptual Framework for the Design of Organizational Control Mechanisms Management Science. 25(9), 833-848 (1979)

8. Morand, D.A.: The Role of Behavioral Formality and Informality in the Enactment of Bureaucratic versus Organic Organizations. Academy of Management Review. 20(4), 831-872 (1995)

9. Martin, J., Knopoff, K., Beckman, C.: An Alternative to Bureaucratic Impersonality and Emotiona Labor: Bounded Emotionality at The Body Shop. Administrative Science Quarterly. 429-469 (1998)

10. Weber, M.: The Theory of Economic and Social Organization. Trans. A.M. Henderson and Talcott Parsons. Oxford University Press, New York (1947)

11. Gerth, H.H., Mills, C.W.: From Max Weber: Essays in Sociology. Trans. H.H. Gerth and Paul Kegan. Oxford University Press, New York (1946)

12. Hochschild, A.R.: The Managed Heart. University of California Press, Berkeley (1983)

13. Clough, P.T. and Halley, J. (eds): The Affective Turn: Theorizing the Social. Duke University Press, Durham, NC (2007)

14. Navaro-Yashin, Y.: Affective Spaces, Melancholic Objects: Ruination and the Production of Anthropological Knowledge. Journal of the Royal Anthropological Institute. 15(1), 1-18 (2009)

15. Reckwitz, A.: Affective Spaces: A Praxeological Outlook. Rethinking History. 16(2), 241-258 (2012)

16. Callon, M.: Some Elements of a Sociology of Translation. In: Law, J. (ed.) Power, Action and Belief: A New Sociology of Knowledge, pp. 196-229. Sociology Review Monograph. Routledge and Kegan Paul, London (1986)

17. Latour, B.: Science in Action: How to Follow Scientists and Engineers Through Society. Harvard University Press, Cambridge, MA (1987)

18. Callon, M.: Techno-Economic Networks and Irreversibility. In: Law, J. (ed.) A Sociology of Monsters: Essays on Power, Technology and Domination, pp. 132-161. Routledge, London (1991) 
19. Akrich, M.: The De-Scription of Technical Objects. In: Bijker. W., Law, J. (eds) Shaping Technology/Building Society, pp. 205-244. MIT Press, Cambridge, MA (1992)

20. Moser, I., Law, J.: Good Passages, Bad Passages. The Sociological Review. 47(S1), 196-219 (1999)

21. Latour, B.: Reassembling the Social: An Introduction to Actor-Network-Theory. Oxford University Press, Oxford and New York (2005)

22. Corbin, J., Strauss, A.: Basics of Qualitative Research: Techniques and Procedures for Developing Grounded Theory. Sage, London and Thousand Oaks, CA (2008)

23. Charmaz, K.: Constructing Grounded Theory: A Practical Guide Through Qualitative Research. Sage, London (2006)

24. Parsons, T.: The Social System. Routledge, London (1951) 